\title{
Zorg voor patiënten na een ic-opname
}

Wytske Geense, Marjolein Siebel, Marianne Brackel, Marieke Zegers, Mark van den Boogaard, Floris van de Laar

Veel mensen kampen in de maanden en jaren na een ic-opname met fysieke, mentale en cognitieve problemen. Dat heeft gevolgen voor gezin en werk. De huisarts speelt een belangrijke rol in het herkennen van deze problematiek en in het samen met de patiënt en diens familie formuleren van behandeldoelen. Het is moeilijk te voorspellen hoe lang post-ic-klachten zullen duren en of ze ooit helemaal verdwijnen. Informeer patiënten hierover en stel gericht kleine, haalbare doelen zodat ze het vertrouwen in het eigen kunnen weer kunnen opbouwen.

\section{MEVROUW VERGEER}

Uw assistente laat mevrouw Vergeer [ 40 jaar] met spoed komen omdat ze zich 'hondsberoerd' voelt tijdens een periode met niersteenaanvallen. $U$ kent haar in verband met een zeer hardnekkige fasciitis plantaris en een ernstige vorm van psoriasis waarvoor zij methotrexaat krijgt van de dermatoloog. In de onderzoekskamer schrikt u van haar toestand. Ze is sloom maar wel alert en maakt inderdaad een zeer zieke indruk. $\mathrm{Na}$ gericht onderzoek stelt u een tachypneu [26/min], tachycardie $[156 / \mathrm{min}]$ en hypotensie $[97 / 74 \mathrm{mmHg}]$ vast, waarop u haar met spoed per ambulance naar het ziekenhuis verwijst.

De dag erop belt u meneer Vergeer. Deze vertelt dat mevrouw kort opgenomen is geweest op de intensive care. Haar sepsis werd veroorzaakt door een pyelonefritis op basis van een niersteen. Ze mocht net van de ic af en het leek wat beter te gaan.

\section{HET POST-INTENSIVECARESYNDROOM [PICS]}

Jaarlijks worden in Nederland ongeveer 80.000 patiënten opgenomen op de intensive care. ${ }^{1}$ De overlevingskansen op de ic zijn sterk toegenomen, tegenwoordig overleeft $90 \%$ van de patiënten hun opname. ${ }^{1}$ Maar er is een keerzijde: de laatste jaren is duidelijk geworden dat de helft van de ic-overlevers nog maanden tot jaren fysieke, psychische of cognitieve problemen houdt [tabel]. Dit wordt wel het post-intensivecaresyndroom (PICS) genoemd. ${ }^{2,3}$

Over PICS zijn in Nederland vooralsnog geen epidemiologische cijfers bekend. Vier jaar geleden heeft het Radboudumc samen met IC Connect en het Family and Patient Centered Intensive Care MONITOR-IC opgezet (www.monitor-ic.nl). Dit is een cohortonderzoek in meerdere centra naar de zelfgerapporteerde uitkomsten van duizenden voormalige ic-patiënten tot 5 jaar na ic-opname. ${ }^{4}$ De eerste resultaten worden binnenkort gepubliceerd. Uit buitenlandse onderzoeken blijkt dat spierzwakte, intensive care acquired weakness (ICUAW), een veelvoorkomend post-ic-probleem is, dat optreedt bij de helft van de patiënten met sepsis, meervoudig orgaanfalen of langdurige beademing. Na 1 week op de ic kunnen patiënten al 15-20\% van hun totale spiermassa kwijt zijn. ${ }^{5}$ ICUAW kan een uiting zijn van critical illness polyneuropathy, critical illness polymyopathy of van beide, en zowel ledematen als ademhalingsspieren (inclusief diafragma) kunnen zijn aangedaan. Ook vermoeidheid, kortademigheid, verminderde conditie, stijfheid in gewrichten en sensorische problemen in handen en voeten komen vaak voor. Risicofactoren zijn immobilisatie, sedatie, hypoxie en gebruik van corticosteroïden. . $^{2,5,6}$

\section{Psychische klachten}

De acute kritieke situatie, pijn, gevoelens van machteloosheid, verlies van autonomie en delier met waanbeelden en hallucinaties maken een ic-opname stressvol. Veel patiënten hebben hierdoor een verhoogd risico op psychische klachten. $\mathrm{Na} 1$ jaar ervaart ruim $30 \%$ symptomen van angst en depressie, en heeft $20 \%$ klachten die passen bij een posttraumatische stressstoornis (PTSS).$^{7-9}$ Deze klachten zijn sterk met elkaar verweven. ${ }^{8}$ Risicofactoren zijn onder andere pre-existente psychiatrische aandoeningen, en tijdens de opname in ic of ziekenhuis benzodiazepinegebruik, delier en symptomen van angst en stress.?

\section{MEVROUW VERGEER, ENKELE WEKEN LATER}

Enkele weken later meldt mevrouw Vergeer zich weer op het spreekuur. Ze heeft klachten die ze nooit eerder heeft gehad en omschrijft zichzelf als 'een wrak'. Er zijn veel lichamelijke klachten zoals hoofdpijn en buikpijn, maar ze is ook erg bang. Ze heeft minder herbelevingen en nachtmerries over de ic-opname dan kort na de opname, maar dit is overgegaan in piekeren en een continu gevoel van bezorgd zijn en catastroferen. Mevrouw Vergeer gaat akkoord met een verwijzing naar de psycholoog in verband met een verhoogde kans op PTSS.

$\mathrm{Na} 4$ sessies bij de psycholoog met onder andere psycho-educatie en eye movement desensitization and reprocessing [EMDR] zijn de angstklachten verminderd. Met mevrouw Vergeer wordt afgesproken dat zij zich kan melden bij de POH-ggz als haar klachten terugkeren, en als dat niet afdoende blijkt zij zich weer kan aanmelden bij de psycholoog. 


\section{DE KERN}

- Een verblijf op de ic, hoe kort ook, kan leiden tot een post-intensivecaresyndroom [PICS], met fysieke, mentale en cognitieve problemen die soms maanden tot jaren aanhouden.

- Het aantal huisartsconsulten is in het jaar na een icopname significant verhoogd, maar de klachten van PICS worden vaak niet in verband gebracht met de ic-opname.

- Familieleden van ic-patiënten kunnen psychische problemen krijgen, zoals angst, depressie en PTSS, en een verstoorde rouwverwerking als hun naaste is overleden.

- De nazorg voor ic-patiënten staat nog in de kinderschoenen, maar de huisarts is bij uitstek in staat om PICS-klachten te herkennen en de patiënt naar de juiste zorg te begeleiden.

\section{Cognitieve problemen}

Voormalige ic-patiënten hebben ook een verhoogd risico op cognitieve problemen, zoals stoornissen van geheugen, concentratie, planmatig denken en uitvoeren. De cijfers in onderzoeken variëren van 4 tot $62 \%$, afhankelijk van de populatie, de gebruikte meetinstrumenten en de gehanteerde definities. Als risicofactoren voor cognitieve problemen worden genoemd delier, sepsis, hypoxie, hypotensie, gebruik van sedativa en analgetica, en hypo- en hyperglykemie. ${ }^{10}$

\section{Dagelijks functioneren}

Al deze lichamelijke, mentale en cognitieve problemen hebben een enorme invloed op het dagelijks functioneren, het gezin, het sociale leven en de werkhervatting. De helft van de voormalige ic-patiënten is na 1 jaar nog niet (volledig) aan het werk en de ervaren kwaliteit van leven is significant lager dan die van vergelijkbare personen in de algemene bevolking. ${ }^{11,12}$

\section{COVID-19}

De langetermijnuitkomsten bij patiënten die vanwege COVID-19 op de ic opgenomen zijn geweest, zijn nog niet bekend maar velen van hen zullen naar verwachting eveneens last krijgen van de genoemde problemen. Hun gemiddelde ligduur op de ic is lang geweest ( 23 dagen), met langdurige beademing en sedatie, en mogelijk blijvende longschade door de infectie en de hoge beademingsdrukken. De kans op mentale problemen door wekenlange eenzaamheid op de ic als gevolg van het bezoekverbod in veel ziekenhuizen en de beschermende kleding van het zorgpersoneel, die communicatie belemmerde en voor veel patiënten beangstigend was, is waarschijnlijk bovengemiddeld. Daarbij hebben veel patiënten door de langdurige sedatie en de ernst van de ziekte een delier doorgemaakt, wat een risicofactor is voor cognitieve problemen op de lange termijn..$^{13,14}$

\section{Familieleden}

Een verblijf op de ic kan ook voor familieleden zeer ingrijpend zijn. ${ }^{15}$ Ook zij kunnen langdurige klachten ontwikkelen zoals slapeloosheid, angst, depressie en PTSS. Daarnaast is de kans op verstoorde rouwverwerking bij overlijden van de naaste verhoogd. Deze problemen, ook wel het post-intensivecaresyndroom-familie (PICS-F) genoemd, kunnen leiden tot baanverlies, financiële problemen en een lagere kwaliteit van leven. ${ }^{16}$

\section{MENEER VERGEER, ENKELE MAANDEN LATER}

Weer enkele maanden later ziet u de meneer Vergeer op het spreekuur. Met zijn vrouw gaat het na de sessies bij de psycholoog een stuk beter, maar nu zit hij zelf ziek thuis. Er is sprake van verdriet, spanning en slecht slapen. Zelf wijt hij dit aan het feit dat zijn vrouw ernstig ziek is geweest en dat het op het werk al langer niet ging. $U$ vraagt de $\mathrm{POH}-$ ggz of zij meneer verder wil begeleiden met zijn klachten.

Tabel

Veelvoorkomende problemen na een ic-opname

\begin{tabular}{|c|c|c|c|}
\hline Fysieke problemen & Psychische problemen & Cognitieve problemen & Sociale problemen \\
\hline $\begin{array}{l}\text { Verminderde conditie } \\
\text { Vermoeidheid } \\
\text { Stijfheid gewrichten } \\
\text { Spierzwakte/ICU verworven spierzwakte } \\
\text { Zenuwpijn } \\
\text { Kortademigheid } \\
\text { Gewichtverlies } \\
\text { Slikproblemen } \\
\text { Zintuiglijke veranderingen [gehoor, smaak, } \\
\text { zicht, reuk, gevoel] } \\
\text { Haaruitval } \\
\text { Verminderde eetlust } \\
\text { Heesheid } \\
\text { Seksuele problemen }\end{array}$ & $\begin{array}{l}\text { Angst } \\
\text { Depressie } \\
\text { Posttraumatische stressstoornis } \\
\text { Nachtmerries/flashback } \\
\text { Slaapstoornis } \\
\text { Stemmingsstoornis } \\
\text { Verhoogde prikkelbaarheid } \\
\text { Overprikkeling door geluid }\end{array}$ & $\begin{array}{l}\text { Geheugenverlies } \\
\text { Aandacht- en concentratiestoornis } \\
\text { Problemen met doelgericht handelen en } \\
\text { plannen van dagelijkse handelingen }\end{array}$ & $\begin{array}{l}\text { Arbeidsongeschiktheid } \\
\text { Verslechtering financiële situatie } \\
\text { Rol in gezin en samenleving aangetast }\end{array}$ \\
\hline
\end{tabular}




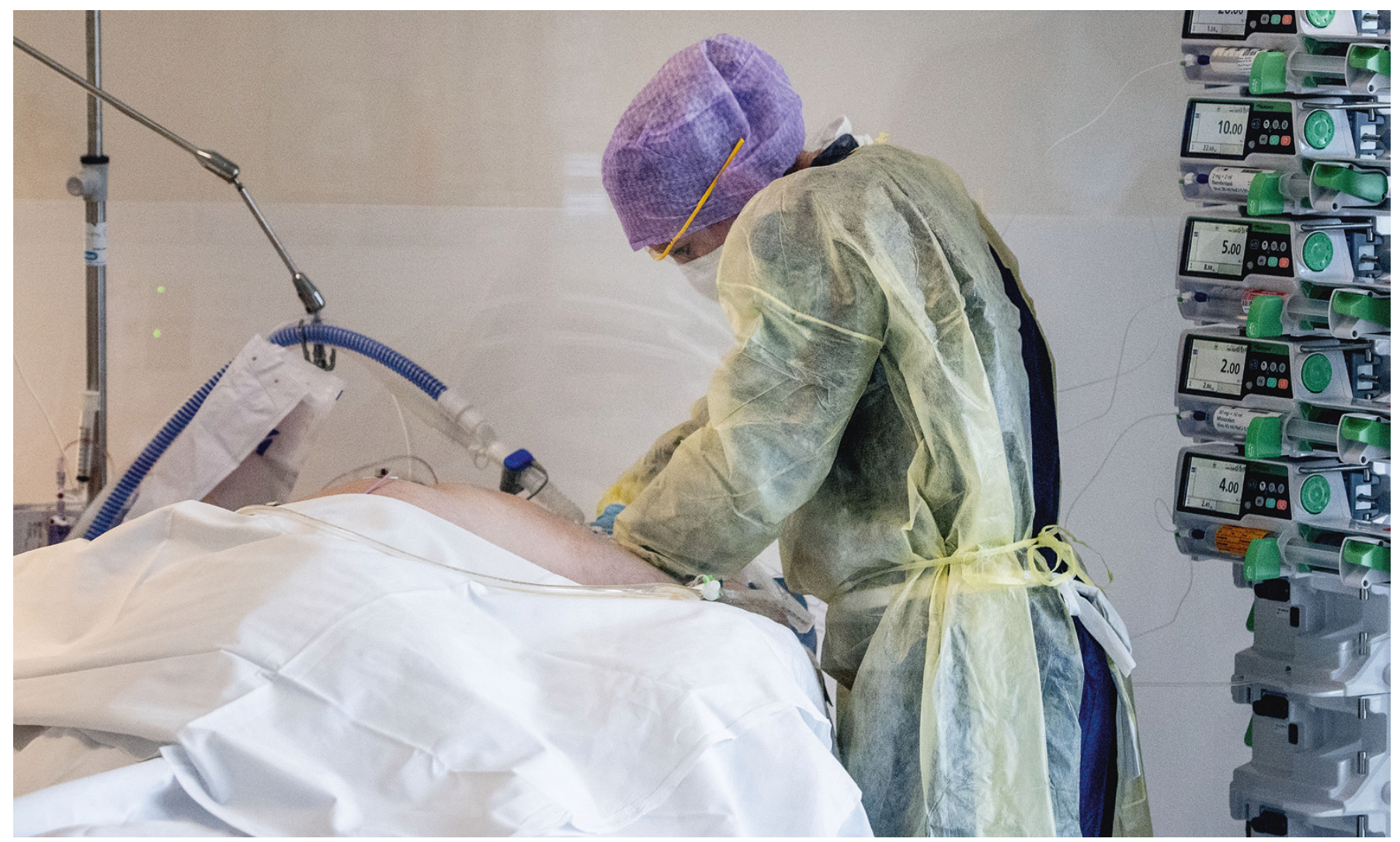

De nazorg voor patiënten die op de ic hebben gelegen staat nog in de kinderschoenen.

Foto: ANP

\section{POST-IC-ZORG IN DE EERSTE LIJN}

Ondanks de enorme hoeveelheid middelen die worden besteed aan betere overlevingscijfers staat de zorg voor de ic-patiënt na de ic nog in de kinderschoenen. ${ }^{17}$ De klachten van PICS worden vaak niet in verband gebracht met de ic-opname. Specifieke nazorg ontbreekt vaak en de nazorg die wel wordt geboden is versnipperd, waardoor patiënten tussen wal en schip vallen. Na de ic wordt de patiënt overgedragen aan de medisch specialist die de onderliggende aandoening behandelt, maar deze is vaak onvoldoende bekend met de uiteenlopende problemen die voormalige ic-patiënten kunnen ervaren..$^{18}$ Steeds meer ziekenhuizen hebben weliswaar een ic-nazorgpoli waar patiënten bijvoorbeeld een ic-verpleegkundige of intensivist kunnen consulteren, maar vaak is dit contact slechts éénmalig. Voormalige ic-patiënten kloppen daarom na hun ontslag vaker bij de huisarts aan: het aantal huisartsconsulten van patiënten in het jaar na een ic-opname is significant hoger dan gemiddeld. ${ }^{19}$ Huisartsenpraktijken leveren nog weinig ic-specifieke nazorg, maar de reguliere huisartsgeneeskundige benadering biedt wel een goede basis voor hulp aan deze groep.

\section{Herkenning en erkenning van post-ic-klachten}

De nazorg voor de patiënt en diens naasten kan al starten tijdens de ic-opname. Weinig huisartsen zullen hun patiënt al op de ic bezoeken, maar een bezoek aan de ic geeft wel inzicht in de ernst van de situatie en in de zorg die na het ontslag nodig zal zijn, niet alleen voor de onderliggende ziekte maar ook voor post-ic-klachten. Kennis over de ic-periode maakt de herkenning en erkenning van zulke klachten makkelijker. Als patiënten hulp vragen na een ic-opname verdient het aanbeveling om goed door te vragen, niet alleen naar somatische klachten die passen bij PICS, maar ook naar angst-, stemmings- en PTSS-klachten, naar concentratie en geheugen, naar de sociale omgeving en naar de werksituatie. Vraag ook hoe het met de gezinsleden gaat. Bij twijfel of de klachten verband houden met de ic-opname is laagdrempelig overleg met de intensivist of de ic-nazorgpoli aan te bevelen.

\section{Therapeutische opties}

De klachten van PICS zijn niet eenduidig en een (eventuele) therapie is dat evenmin. Begin met een goede verheldering van de hulpvraag en formuleer op basis daarvan samen met de patiënt behandeldoelen. Afhankelijk van deze doelen kan een plan worden gemaakt, dat altijd (ook) bestaat uit psycho-educatie. Er zijn diverse opties voor aanvullende hulp en het is goed om in kaart te brengen welke hulpverleners in het netwerk kenmerkende post-ic-klachten kunnen behandelen. Voor somatische problematiek valt te denken aan fysio- en oefentherapie (moeheid, zwakte, conditie), logopedie (heesheid, slik- en eetproblemen) en diëtetiek (eetlust, gewichtsverlies). Voor sociale problematiek kan maatschappelijk werk worden ingeschakeld, angst- en stemmingsklachten kunnen door een POH-ggz of eerstelijnspsycholoog worden behandeld. Voor cognitieve problemen zou een medisch psycholoog geconsulteerd kunnen worden, eventu- 


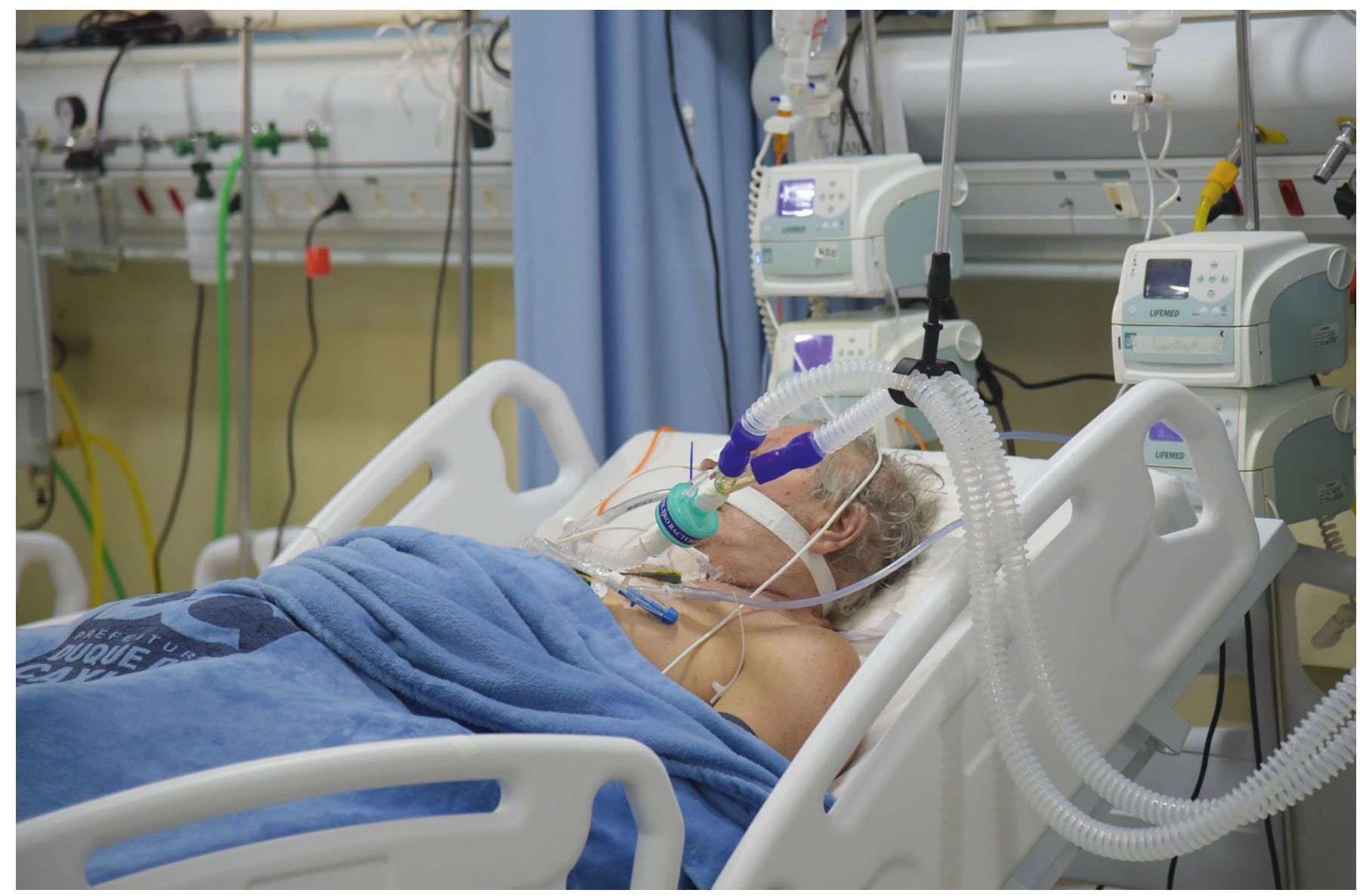

Het is moeilijk te voorspellen hoe lang post-ic-klachten duren en of de klachten ooit helemaal verdwijnen.

Foto: Shutterstock

eel via het ziekenhuis. Bij stagnerend herstel of persisterende aanpassingsproblemen kan ook een rol zijn weggelegd voor ergotherapie of voor revalidatieprogramma in de eerste of tweede lijn.

Patiënten kunnen verder baat hebben bij voorlichtingsmateriaal van patiëntenorganisaties en lotgenotencontact via ICCafés, bijeenkomsten die worden georganiseerd door verschillende ziekenhuizen. Een Nederlandse richtlijn voor ic-nazorg en revalidatie is in de maak.

\section{CONCLUSIE}

Veel mensen kampen in de maanden en jaren na hun icopname met fysieke, mentale of cognitieve problemen die sociale, maatschappelijke en financiële gevolgen hebben. De huisarts speelt een belangrijke rol in het herkennen van deze problematiek en in het samen met de patiënt en diens familie formuleren van behandeldoelen. Bij het zoeken naar passende hulp valt te denken aan overleg met of verwijzing naar een post-ic-poli, of aan gericht doorverwijzen naar bijvoorbeeld een fysiotherapeut, diëtist, logopedist, ergotherapeut of psycholoog. Het is moeilijk te voorspellen hoe lang post-icklachten duren en of de klachten ooit helemaal verdwijnen. Het helpt patiënten om het vertrouwen in het eigen kunnen weer op te bouwen als men ze hierover informeert en gericht kleine, haalbare doelen stelt. -

\section{LITERATUUR}

1. Basisgegevens IC units voor het jaar 2018. Amsterdam: Nationale Intensive Care Evaluatie (NICE), 2018.

2. Needham DM, Davidson J, Cohen H, et al. Improving long-term outcomes after discharge from intensive care unit: report from a stakeholders' conference. Crit Care Med 2012;40:502-9.

3. Post Intensive Care Syndroom (PICS). Alkmaar: Family and Patient Centered Intensive Care, 2020. https://fcic.nl/postintensive-care-syndroom, geraadpleegd oktober 2020.

De volledige literatuurlijst staat bij dit artikel op www.henw.org.

Geense WW, Siebel MH, Brackel M, Zegers M, Van den Boogaard M, Van de Laar FA. Zorg voor patiënten na een ic-opname. Huisarts Wet 2021;64[2]:39-42. D0l:10.1007/s12445-020-1000-3.

Radboudumc, afdeling Intensive Care, Nijmegen: W.W. Geense, promovendus: wytske.geense@radboudumc.nl; dr. M. Zegers, senior onderzoeker; dr. M. van den Boogaard, senior onderzoeker. Stichting FCIC, Projectgroep Nazorg: M.H. Siebel, kerngroeplid. IC Connect: M. Brackel, voorzitter. Academisch Gezondheidscentrum Thermion, Lent/ Radboudumc, afdeling Eerstelijnsgeneeskunde, Nijmegen: dr. F.A. van de Laar, huisarts en senior onderzoeker.

Mogelijke belangenverstrengeling: niets aangegeven. 